\title{
Drug utilization in primary healthcare centres in the Gaza Strip
}

Shereen W. Ayoub ${ }^{1}$, Areej H. Musalam ${ }^{2}$ and AshrafA. Abu Mahadi ${ }^{2}$

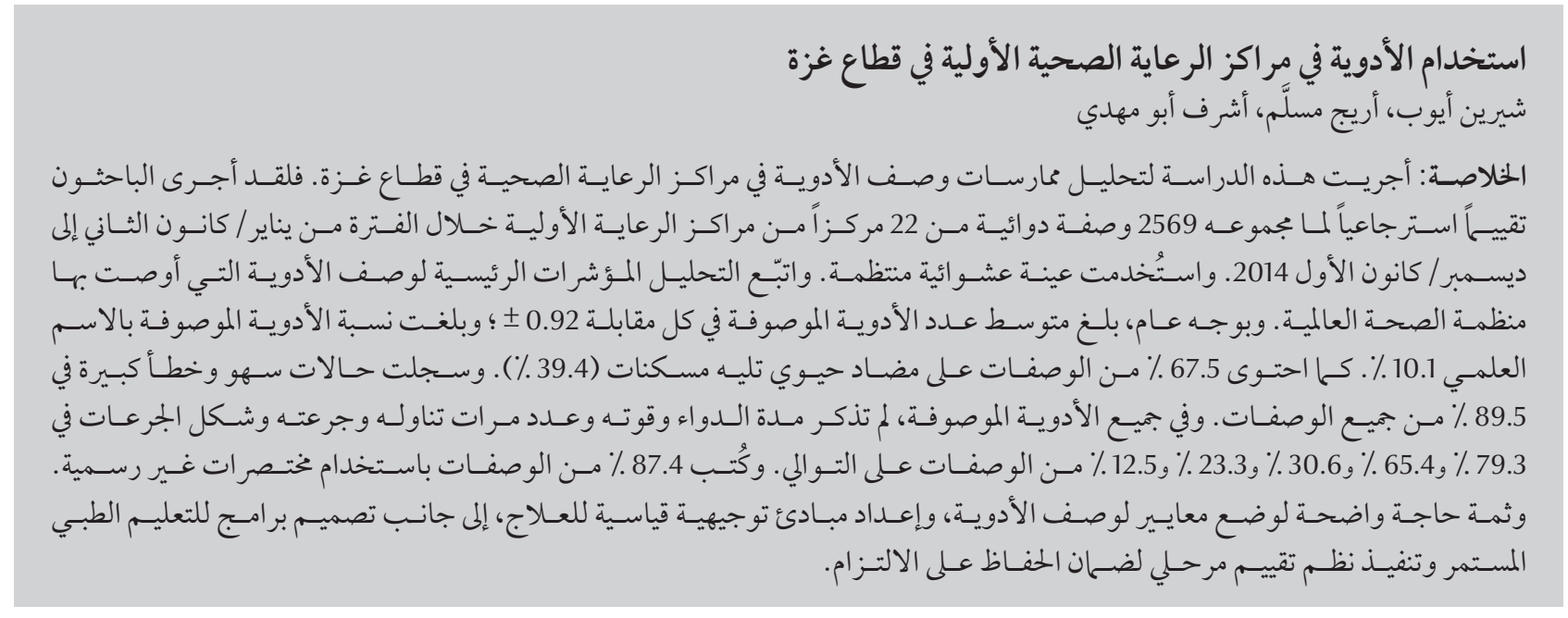

ABSTRACT This study was carried out to analyse drug-prescribing practices in primary healthcare centres (PHCs) in the Gaza Strip. We retrospectively evaluated 2569 prescriptions from 22 PHCs during January-December 2014. Systematic random sampling was applied. Analysis followed the World Health Organization recommended core prescribing indicators. The mean number of drugs prescribed per encounter was 2 (standard deviation 0.9); the percentage of drugs prescribed by generic name was $10.1 \%$; and $67.5 \%$ of prescriptions contained an antibiotic followed by analgesics (39.4\%). Major omission errors were found in $89.5 \%$ of all prescriptions. For all drugs prescribed, drug duration, strength, frequency, dose and dosage form were not mentioned in $79.3 \%, 65.4 \%$, $30.6 \%, 23.3 \%$ and $12.5 \%$ of prescriptions, respectively. Nonofficial abbreviations were used to write $87.4 \%$ of prescriptions. There is a clear need to develop standards for drug prescribing, standard treatment guidelines for drug use, along with continuing medical education programmes, and the implementation of monitoring systems to ensure that they are adhered to.

\section{L'utilisation des médicaments dans les centres de soins de santé primaires de la Bande de Gaza}

RÉSUMÉ La présente étude a été réalisée pour analyser les pratiques de prescription de médicaments dans les centres de soins de santé primaires de la Bande de Gaza. Les chercheurs ont analysé rétrospectivement 2569 prescriptions provenant de 22 centres sur la période allant de janvier à décembre 2014. La méthode d'échantillonnage aléatoire systématique a été appliquée. L'analyse a utilisé les indicateurs fondamentaux de prescription recommandés par l'Organisation mondiale de la Santé (OMS). Dans l'ensemble, le nombre moyen de médicaments prescrits par visite était de 2 (Écart-type 0,9), le pourcentage de médicaments génériques prescrits étant de $10,1 \% ; 67,5 \%$ des prescriptions contenaient des antibiotiques suivis par des analgésiques pour $39,4 \%$. Des oublis majeurs ont été trouvés dans $89,5 \%$ des prescriptions. Pour tous les médicaments prescrits, la durée, la puissance, la fréquence du traitement, la posologie et la forme galénique n'étaient pas mentionnées dans $79,3 \%, 65,4 \%, 30,6 \%, 23,3 \%$ et $12,5 \%$ des prescriptions respectivement. Les abréviations officielles n'étaient pas utilisées dans $87,4 \%$ des prescriptions. Il existe un besoin évident d'élaborer des normes pour la prescription de médicaments, des directives thérapeutiques standard sur l'utilisation des médicaments ainsi que des programmes de formation médicale continue, et de mettre en place de systèmes de suivi pour garantir l'observance thérapeutique.

'Department of Pharmacology, Faculty of Human Medicine, Al-Azhar University, Gaza Strip, Palestine (Correspondence to: Shereen Ayoub: shereenayoub_2002@yahoo.de). ${ }^{2}$ General Administration of Pharmacy, Ministry of Health, Gaza Strip, Palestine.

Received: 04/07/15; accepted: 27/02/17 


\section{Introduction}

Rational prescribing and rational drug use are important goals that all healthcare systems should endeavour to achieve, irrespective of a country's degree of development. Rational drug use means that appropriate medicines are prescribed in the correct dose and dosage form to the correct patient and at the lowest cost to the patient and the community. When one or more of these conditions is lacking, irrational use of drugs will arise (1). Worldwide, $>50 \%$ of all medicines are prescribed, dispensed or sold inappropriately, while $50 \%$ of patients fail to take them correctly $(1,2)$. Unfortunately the availability and irrational use of drugs is a major problem in current medical practice and its consequences include the development of resistance to antibiotics, ineffective treatment, adverse effects, drug dependence and an economic cost to the patient and society. Irrational or misuse of drugs refers to the distribution or consumption of drugs in ways that negate or reduce their efficacy or in cases where they are unlikely to have the desired effect (1-3). To achieve optimal availability and appropriate use of drugs, a national drug policy is required to cover drug quality, safety, efficacy, availability and affordability $(4,5)$. This drug policy should conform with the principles of primary health care (PHC), including the availability of essential drugs and the promotion of the rational distribution and utilization of drugs (6).

The Palestine Ministry of Health $(\mathrm{MoH})$ established the first Palestinian National Drug Policy in 1996. In 2000 an Essential Drug List (EDL) was developed. However, the EDL has not been updated since. Furthermore, the Gaza Strip lacks an appropriate policy, standard treatment guidelines and training programmes for health staff regarding prescribing, dispensing and use of drugs (7).
Officially, the General Administration of Pharmacy in the Gaza Strip is responsible for the procurement and supply of pharmaceuticals in public sector facilities. The $\mathrm{MoH}$ buys the majority of medicine and medical disposables listed on the EDL through an annual tender according to the requirements of clinics and hospitals in the West Bank and Gaza Strip. Since 2007, the $\mathrm{MoH}$ in Ramallah has been responsible for sending regular shipments of drugs and medical disposables to the central stores in the Gaza Strip in order to provide $\mathrm{MoH}$ facilities with their requirements. In practice, the shipments of medicines and medical disposables are neither regular nor contain sufficient quantities to meet those needs. This situation results in the steady deterioration of stocks of medicines and medical disposables in MoH facilities in the Gaza Strip (7). In general practice, the $\mathrm{MoH}$ in the Gaza Strip acquires pharmaceuticals in 3 ways: (1) it receives a significant part of its medicines through donations; (2) it procures some badly needed items itself to compensate for the shortage; and (3) it receives official shipments from the MoH in Ramallah $(8,9)$.

Because prescribing and dispensing and the use of drugs by patients in the Gaza Strip is not well documented, the present study was conducted in PHCs to provide information about basic indicators of drug use in the context of patient treatment. These indicators are used to measure performance in 3 areas relating to the rational use of drugs in healthcare facilities: (1) prescribing indicators measure the performance of prescribers; (2) patient care indicators measure what patients experience in healthcare facilities; and (3) facility indicators measure whether the health personnel can function effectively (2). A detailed manual on their application is available from WHO (10). In addition, in this study the number of drugs prescribed, the percentage of antibiotics and analgesics prescribed for different age groups of patients, the reasons for attending a PHC, and the prescription writing skills in PHCs were measured to obtain preliminary data for promoting rational use and prescribing patterns in the PHCs.

\section{Methods}

This study was carried out during the siege of the Gaza Strip in 2014, when there was a drastic shortage of $\mathrm{MoH}$ EDL drugs. A cross-sectional study of 1-year duration was undertaken over the course of 2014. A form was designed for data collection adapted from the WHO manual "How to investigate drug use in health facilities: selected drug use indicators". Indicators relating to prescribing practice were selected, and the principle investigator visited government outpatient pharmacies in PHCs for data collection (10). The number of drugs prescribed per patient, the percentage of antibiotics and analgesics prescribed for different age groups, the reasons for attending a PHC, and the prescription writing skills in PHCs were documented. Prescribing errors were classified according to the following criteria: absence, vague, incomplete and/or illegibility of any component of the body of the prescription were considered to be major errors of omission. Absence of any of the prescription components such as date of prescription, patient's personal identifiers, physician's stamp, and/or direction for use were deemed to be minor errors of omission $(11-14)$.

\section{Sampling and data collection}

The sampling frame consisted of 56 PHCs in the Gaza Strip using a systematic random sampling method. The sample was selected from the numbered list of all PHCs in the Gaza Strip arranged in order from north to south by using a regular interval starting from a random starting point as follows. (1) To calculate the sampling interval, we divided the size of the list by the 
desired sample size, so our sampling interval was $56 / 22=2.55$. (2) Choose a random number between 0 and 1 (with at least 3 digits after the decimal point, such as 0.657 ), then multiply this random number by the sampling interval, and round this result upward to obtain the number of the first centre $(0.657$ $\times 2.55=1.67535 \square 2$ ), so the second centre in the list was our first sample. (3) Later centres were selected by adding the sample interval to the previous result (1.67535), then the next centre selected would be $1.67535+2.55=4.22$ $\square 5$, and so on. (4) Within the PHC the sample of prescriptions was selected using randomized systematic sampling where only 10 prescriptions were selected from each month throughout the year.

Sample size: the sample of prescriptions was selected by using a systematic simple random sampling technique. Twenty-two PHCs with 115-120 patient prescriptions per centre, with an average of 10 prescriptions per month throughout 2014 were selected.

Sample collection: the data were collected retrospectively. Two work teams, each consisting of 2 pharmacists, were trained to collect data by attending a workshop held at the General Administration of Pharmacy, Palestinian Ministry of Health, Gaza Strip. Prior to data collection, a pilot study was conducted at 2 centres to test the study design procedure and provide feedback about the positive and negative aspects of the form design.

Exclusion criteria: only prescriptions dispensed directly to patients by pharmacists were included in the study, whereas prescriptions containing injections to be given to patients by the nursing staff in PHCs were excluded.

\section{Calculation of indicators}

Throughout the study we followed the methodology recommended by the WHO. Indicators were calculated in the following way: (1) average number of drugs per encounter $=$ total number of drugs prescribed/total number of encounters surveyed; (2) percentage of drugs prescribed by generic name $=$ (number of drugs prescribed by generic name/total number of drug prescribed) $\times 100$; (3) percentage of encounters with an antibiotic prescribed $=$ (number of patient encounters with an antibiotic prescribed/total number of encounters surveyed) $\times 100$; (4) percentage of encounters with an injection prescribed $=$ (number of patient encounters with an injection prescribed/total number of encounters surveyed) $\times 100$; and $(5)$ percentage of drugs prescribed from the $\mathrm{EDL}=$ (number of drugs prescribed from the EDL/total number of prescribed drugs) $\times 100$.

\section{Statistical analysis}

The data were analysed using IBMSPSS version 19 , after manual verification and cleaning. Descriptive statistics [means, percentages and standard deviations (SDs) ] were used to present the results.

\section{Ethical consideration}

Ethical approval for the study protocol was granted by the Palestinian $\mathrm{MoH}$ prior to commencement of the study.

\section{Results}

In this study, 2569 prescriptions from 22 PHCs were collected and analysed: 1226 (47.7\%) of them were for male patients and 1343 (52.3\%) for female patients. The mean age of the patients was 22.6 (SD 22.7) years, ranging across the PHCs from a mean of 15.4 to 33 years. Table 1 represents the results for each PHC and for all centres combined.

A total of 5074 drugs were prescribed. The overall mean number of drugs prescribed per encounter was 2 (0.9), with a range across the $22 \mathrm{PHCs}$ from 1.7 to 2.4. From the total number of prescriptions, $23.7 \%$ specified $\geq 3$ drugs, and only $6.2 \%$ specified $\geq 4$ drugs (Table 2).
The percentage of drugs prescribed by generic name was $10.1 \%$ (3.2-19.1\%), whereas the percentage of EDL drugs prescribed was $81 \%$ (68.6$90.2 \%)$. The percentage of prescriptions for antibiotics was $67.5 \%(53.3-78.3 \%)$, for analgesics $39.4 \%$ (28.3-56.7\%) and for injections 1.3\% (0-4.2\%) (Table 1).

Studying the number of drugs prescribed for different age groups of patients, we found that the mean number of drugs per prescription for patients $\leq 3$ years of age was [2.1 (0.9)], which is similar to that for patients aged $\leq 55$ years $[2.1(1.1)]$. The highest percentage of prescriptions containing 2, 3 and 4 drugs was for patients $\leq 3$ years of age, followed by patients $\geq 55$ years of age, whereas the highest percentage of prescriptions containing 4 and 5 drugs was for patients aged $\geq 55$ years (Table 3 ).

Studying the percentage of antibiotics and analgesics prescribed for different age groups of patients, we found that for patients $\leq 3$ years of age the percentage of prescriptions with analgesics was $43.1 \%$, and the percentage of prescriptions with antibiotics was $39.9 \%$, which is the highest percentage among all age groups (Table 4).

The most common reasons for attending a PHC were infectious disease (51.2\%), followed by chronic disease (7.9\%), and other diseases (4\%) including anaemia, burns, fever, constipation and psoriasis. However, $28.1 \%$ of all prescriptions did not contain a diagnosis and therefore the reason for attendance was not known.

Infectious disease was distributed over the following categories: $28.9 \%$ respiratory tract infections (26.2\% upper and $2.7 \%$ lower respiratory tract); $22.3 \%$ other infections, including gastroenteritis (6.6\%), urinary tract infection (3.5\%), skin infection (2.9\%), conjunctivitis (1.3\%) and auditory tract infection (1.2\%). Patients with more than 1 infection accounted for $1.5 \%$ of prescriptions. A further $3.2 \%$ accounted for other microbial infections such as 


\begin{tabular}{|c|c|c|c|c|c|c|c|c|}
\hline \multirow[t]{2}{*}{$\begin{array}{l}\text { Centre } \\
\text { No. }\end{array}$} & \multirow{2}{*}{$\begin{array}{c}\text { Patients' age } \\
(y r)\end{array}$} & \multirow{2}{*}{$\begin{array}{l}\text { No. of drugs per } \\
\text { encounter } \\
\text { Mean (SD) }\end{array}$} & \multirow[t]{2}{*}{$\begin{array}{l}\text { No. of drugs in } \\
\text { prescriptions }\end{array}$} & \multicolumn{3}{|c|}{$\%$ of encounter with } & \multicolumn{2}{|c|}{$\begin{array}{l}\% \text { of drugs } \\
\text { prescribed in }\end{array}$} \\
\hline & & & & $\mathbf{A B}$ & AN & INJ & GN & EDL \\
\hline 1 & $15.4(19.4)$ & $2.0(0.9)$ & 235 & 71.4 & 33.6 & 0.8 & 19.2 & 83.4 \\
\hline 2 & $18.7(21.7)$ & $1.8(0.8)$ & 221 & 63.3 & 35.8 & 0.8 & 12.2 & 87.8 \\
\hline 3 & $23.8(23.0)$ & $1.9(0.9)$ & 223 & 60.0 & 36.7 & 0.8 & 18.8 & 87.0 \\
\hline 4 & $20.3(24.0)$ & $1.8(0.8)$ & 221 & 67.5 & 38.3 & 0.8 & 3.2 & 85.5 \\
\hline 5 & $22.3(22.2)$ & $2.0(1.0)$ & 236 & 64.2 & 35.8 & 0.0 & 14.8 & 77.5 \\
\hline 6 & $27.0(23.8)$ & $2.0(0.9)$ & 237 & 60.8 & 42.5 & 0.0 & 5.9 & 78.9 \\
\hline 7 & $19.5(20.2)$ & $2.1(1.0)$ & 251 & 78.3 & 36.7 & 0.0 & 7.6 & 85.7 \\
\hline 8 & $24.9(22.8)$ & $2.1(1.0)$ & 256 & 59.2 & 56.7 & 3.3 & 10.2 & 84.4 \\
\hline 9 & $22.3(21.7)$ & $1.7(0.8)$ & 206 & 75.8 & 33.3 & 1.7 & 9.2 & 89.3 \\
\hline 10 & $25.4(24.2)$ & $1.9(1.0)$ & 228 & 61.7 & 41.7 & 2.5 & 12.3 & 81.6 \\
\hline 11 & $20.5(20.1)$ & $1.9(0.8)$ & 223 & 71.7 & 41.7 & 0.0 & 9.9 & 77.1 \\
\hline 12 & $22.1(22.6)$ & $2.0(0.9)$ & 236 & 75.8 & 35.8 & 0.8 & 6.8 & 68.6 \\
\hline 13 & 15.4 (19.1) & $2.1(0.9)$ & 254 & 78.3 & 52.5 & 0.0 & 9.8 & 70.9 \\
\hline 14 & $31.2(23.3)$ & $2.0(0.9)$ & 239 & 53.3 & 28.3 & 4.2 & 4.6 & 78.7 \\
\hline 15 & $18.5(20.5)$ & $2.0(0.9)$ & 215 & 70.9 & 35.5 & 0.0 & 7.0 & 73.5 \\
\hline 16 & $24.1(23.3)$ & $2.0(1.0)$ & 245 & 67.5 & 28.3 & 3.3 & 5.3 & 78.8 \\
\hline 17 & $25.6(24.2)$ & $2.3(1.0)$ & 276 & 73.3 & 48.3 & 2.5 & 7.3 & 77.2 \\
\hline 18 & $25.3(24.7)$ & $2.4(1.0)$ & 286 & 71.7 & 43.3 & 2.5 & 17.5 & 83.6 \\
\hline 19 & $19.6(22.8)$ & $1.7(0.7)$ & 204 & 62.5 & 40.8 & 1.7 & 10.3 & 90.2 \\
\hline 20 & $16.9(20.1)$ & $1.9(0.7)$ & 111 & 71.7 & 41.7 & 3.3 & 15.3 & 82.0 \\
\hline 21 & 22.0 & $1.8(1.0)$ & 214 & 66.7 & 34.2 & 0.0 & 11.2 & 77.1 \\
\hline 22 & $33.0(24.5)$ & $2.1(1.0)$ & 257 & 61.7 & 45.8 & 0.0 & 10.9 & 83.3 \\
\hline Total & $22.6(22.7)$ & $2.0(0.9)$ & 5074 & 67.5 & 39.4 & 1.3 & 10.1 & 81.0 \\
\hline
\end{tabular}

$A B=$ antibiotics $; A N=$ analgesics $; E D L=$ essential drug list $G N=$ generic name; $I N J=$ injections; $S D=$ standard deviation.

viral, fungal and other bacterial infections such as appendicitis, folliculitis, mastitis, pulpitis and stomatitis.

In our sample, 5074 drugs were prescribed, among which antibiotics were the most commonly prescribed (40.9\%), followed by analgesics (20.8\%), dermatological preparations (5.6\%) and antihistamines (4.5\%) (Figure 1).
Regarding prescription writing skills in PHCs, $89.5 \%$ of prescriptions contained major omission errors: the length of treatment was omitted in $79.3 \%$, the strength of medications was omitted in $65.4 \%$ of prescriptions, the dosing frequency was omitted in $30.6 \%$, the dose was not specified in $23.3 \%$ and the dosage form was not specified in $12.5 \%$. Nonofficial abbreviations were used in writing $87.4 \%$ of all prescriptions, while

\begin{tabular}{lc}
\hline Table 2 Percentage of prescriptions according to number of drugs per prescription \\
\hline No. of drugs per prescription & $(\%)$ \\
1 & 33.9 \\
2 & 42.5 \\
3 & 17.5 \\
4 & 4.9 \\
$>4$ & 1.3 \\
\hline
\end{tabular}

$18.7 \%$ were written in illegible handwriting. There were minor omission errors such as the absence of a physician's signature, date of prescription and patient's age, but the number of such cases was insignificant in comparison.

\section{Discussion}

Our study is an attempt to investigate current drug use patterns in PHC facilities in the Gaza Strip. Data for this study, 2569 prescriptions from 22 PHCs in the Gaza Strip, were collected and analysed retrospectively according to the recommended WHO core indicators (10). The mean age of patients identified in this study was 22.6 (22.7) years.

The WHO standard values for the average number of drugs per encounter 


\begin{tabular}{lccccc}
\hline Table 3 Relationship between patient age and number of drugs per prescription & \multicolumn{1}{c}{} \\
No. of drugs per prescription & $\mathbf{2}$ & $\mathbf{3}$ & $\mathbf{4}$ & $\mathbf{5}$ & $\mathbf{6}$ \\
Age interval (yr) & $(\%)$ & $(\%)$ & $(\%)$ & $(\%)$ & $(\%)$ \\
$\leq 3$ & 36.1 & 44 & 35.2 & 34.6 & 0 \\
$4-15$ & 19.4 & 13.8 & 7.2 & 7.7 & 0 \\
$16-25$ & 10.3 & 10 & 7.2 & 0.0 & 14.3 \\
$26-35$ & 10.6 & 7.8 & 9.6 & 0.0 & 0 \\
$36-45$ & 7.9 & 7.3 & 11.2 & 7.7 & 7.7 \\
$46-55$ & 6.0 & 6.2 & 8.8 & 7.3 & 42.9 \\
$>55$ & 9.6 & 10.9 & 20.8 & 42.3 & 28.6 \\
\hline
\end{tabular}

is 1.6-1.8 (15), whereas in our study the mean number of drugs prescribed per encounter was 2 (0.9). This value falls near the midpoint of results reported by investigators from Sudan (1.4) (16), Zimbabwe (1.3) (17), Saudi Arabia (1.4) (18), Yemen (1.5) (10), Lebanon (1.6) (19), Jordan (2.3) (20), Bahrain (3.3) (21) and Nigeria (3.8) (10).

In this study, polypharmacy $(\geq 3$ drugs) was observed in only $23.7 \%$ of prescriptions, with only $6.2 \%$ of them specifying $\geq 4$ drugs. This may be an apparent value and not a real value in the Gaza Strip. This low number of drugs per encounter may be related to drug shortage or the fact that some drugs are not actually prescribed because they are not on the EDL. In the latter case the patient may nevertheless be advised by the physician in the PHC to buy them directly from a community pharmacy.

The overall percentage of drugs prescribed by generic name was $10.1 \%$, which is similar to that of Bahrain (10.2\%) (21). Drugs prescribed by generic name vary widely between countries. In some it is high: Niger (100\%) (22), Zimbabwe (94\%) (17) and Tanzania (82\%) (17). In others it is low, but still higher than in our study, as in Bangladesh (78\%) (23), Sudan (19.5\%) (16) and Saudi Arabia (15.1\%) (24); whereas Jordan (5.1\%) (20) and Lebanon (2.9\%) (19) are even lower than in our study.

In practice, physicians in $\mathrm{PHC}$ facilities in the Gaza Strip almost always use trade names in prescribing. This explains the low percentage of drugs prescribed by generic name, which can be attributed to the influence of the marketing strategy of pharmaceutical sales representatives.

Palestinian $\mathrm{MoH}$ guidelines are required to enforce prescribing by generic name; particularly in the public sector.

In this study, antibiotics accounted for $40.9 \%$ of the total of medication expenditure, followed by analgesics (20.8\%). The prescribing of antibiotics accounted for $67.5 \%$ of all prescriptions, ranging from 53.3 to $78.3 \%$. This value is high, as the $\mathrm{WHO}$ expectation is $15-25 \%$ in most countries where infectious disease is more prevalent $(10,25)$. In comparison, this value $(67.5 \%)$ is slightly higher than for Jordan (60.9\%) (20) and Yemen (46.5\%) (10) but it is extremely high when compared to that of Lebanon (17.5\%) (19). The misapplication of antibiotics in clinical medicine is a global phenomenon and this misuse is sometimes related to underdosing, short duration and/or use for nonbacterial infections. This has led to the emergence of bacterial resistance.

In the Gaza Strip the excessive use of antibiotics is due to the lack of an appropriate policy, the absence of standard treatment guidelines and the lack of physician training regarding antibiotic use. Moreover, patients can obtain antibiotics from a community pharmacy without a prescription even when unnecessary or inappropriate. Furthermore, patients believe that antibiotic use is helpful in rapid amelioration of their symptoms.

In our study the percentage of prescribed injections was low (1.3\%), compared with both the international average of $17 \%$ and that of other developing countries such as Nepal (5\%) (17), Zimbabwe (11\%) (17) and Bahrain $(9.3 \%)(21)$, but similar to that for Jordan (1.2\%) (20). This low percentage of prescribed injections in our study may have been due to the fact that the cost of injection therapy is higher than oral dosage form. Patients requiring

\begin{tabular}{lcc}
\hline \begin{tabular}{l} 
Table $\begin{array}{l}\text { Relationship between patient age and percentage of antibiotics and } \\
\text { analgesics prescribed }\end{array}$ \\
\hline Age interval (yr)
\end{tabular} & $\begin{array}{c}\text { \% of prescriptions with } \\
\text { analgesics }\end{array}$ & $\begin{array}{c}\text { \% of prescriptions with } \\
\text { antibiotics }\end{array}$ \\
$\leq 3$ & 43.1 & 39.9 \\
$4-15$ & 16.5 & 21.1 \\
$16-25$ & 9.3 & 10.7 \\
$26-35$ & 9.1 & 9.5 \\
$36-45$ & 7.0 & 8.1 \\
$46-55$ & 5.7 & 5.2 \\
$>55$ & 9.3 & 5.5 \\
\hline
\end{tabular}




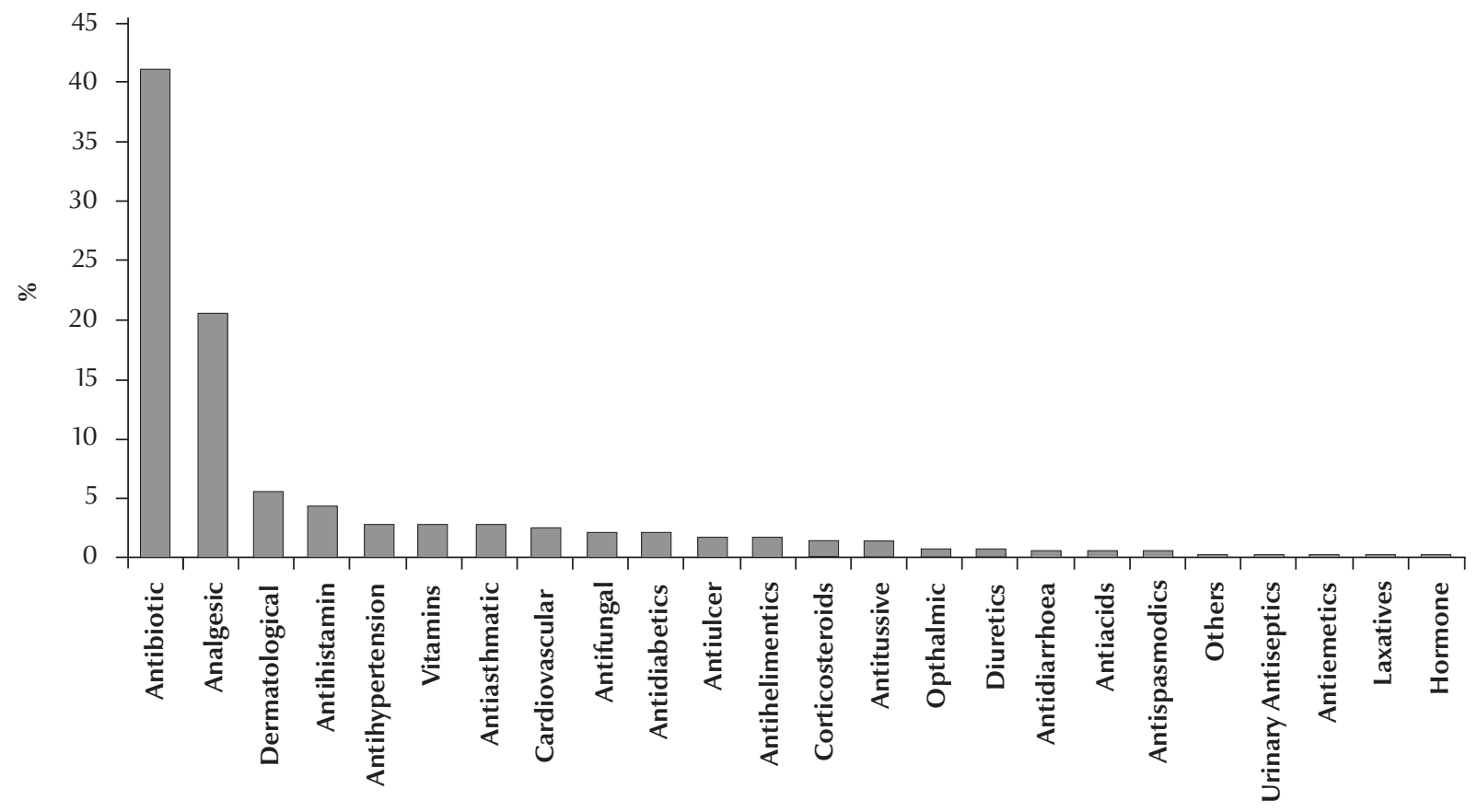

The prescriped group of medication

Figure 1 Classification of drugs prescribed by PHCs

parenteral therapy (except for insulin and emergency situations) should be referred to a hospital and prescriptions for injections administered in the PHC are not available in pharmacies.

In this study $81 \%$ of prescribed drugs were EDL drugs while the remaining $19 \%$ were non-EDL drugs. In general, non-EDL drugs are not allowed to be prescribed within $\mathrm{PHC}$ facilities. In reality, patients are advised to buy them directly from a community pharmacy, as it is still possible in the Gaza Strip to obtain prescription-only medication without prescription (verbally or by illegal prescription). The non-EDL drugs illicitly prescribed by PHC facilities (19\%) came from donations. Donations are not always well coordinated with the $\mathrm{MoH}$ and some donated items are not on the EDL. Because of the retrospective nature of our study it is difficult to determine the actual number of non-EDL drugs prescribed.

Studying the relationship between age and number of drugs per prescription, we found a clear tendency toward prescribing a greater number of drugs in the age group $\leq 3$ years, with a mean number of drugs per prescription of 2.1 (0.9), which is similar to that for patients in the age group $\geq 55$ years [2.1 (1.1)]

The highest percentages of antibiotics and analgesics were prescribed for patients aged $\leq 3$ years. Multiple drug prescriptions for older patients can be explained by patients taking 1 or more prescription drugs plus several overthe-counter drugs, such as antacids and analgesics, whereas the high use of multiple drug prescriptions for patients in the age group $\leq 3$ years is unclear. The latter may be due to the co-payment differences among different age groups. An insured patient has to pay 0.3 US\$ for 2 medicines for children aged $\leq 3$ years and 0.3 US\$ for each extra medicine, but 0.8 US\$ for each unit medicine for patients aged $>3$ years. As a consequence, 1 or more drugs prescribed for patients aged $\leq 3$ years may be intended for other family members (26).

A prescription is a legal document that may be used either for or against both physician and pharmacist in cases related to prescribing or dispensing errors. Prescribing errors may have serious consequences, therefore, all prescription components have to be clearly written, free of any nonofficial abbreviations, and fulfil the legal requirements. Incorrectly written components of the body of the prescription are considered an error of commission (27-29). Errors of integration or knowledge-based errors in prescribing include potential drug-drug interactions or drug allergies that may reflect a failure of the prescriber to integrate information about the patient or drug history. Other prescription errors include prescriptions with illegible handwriting or with nonofficial abbreviations (30).

One of the aims of our study was to recognize deficiencies in prescribing and to investigate the prescription writing skills of physicians, regardless of the nature of patients' conditions. We found that the prescription writing skills in PHCs were suboptimal. Even though diagnosis is 1 of the main components 
of the PHC prescription form, assisting the pharmacist to ensure that the prescribed drugs are suitable for the patients' conditions, the diagnosis was omitted in $28.1 \%$ of all prescriptions.

It is worth mentioning that the shortage of MoH EDL drugs may have affected the results of this study. Had more EDL drugs been available, perhaps more drugs and more antibiotics would have been prescribed. Our results illustrate the urgent need for extensive improvement in prescribing practice as a considerable proportion of prescriptions lacked essential information.

\section{Conclusion and Recommendations}

Our study of drug-prescribing patterns in PHCs in the Gaza Strip clearly demonstrates that there is an irrational use of drugs. It is our opinion that there is a need to develop standards for drug prescription as well as standard treatment guidelines for drug use and for supervision and monitoring systems to ensure that they are adhered to. Furthermore, continuing medical education programmes are required to develop awareness about polypharmacy, irrational drug use, good prescribing and the necessity of an auditing system.
Finally, this study needs to be extended and repeated over time to assess the improvement in drug prescribing and use.

\section{Acknowledgements}

We are grateful to our colleague Dr. Nedaa Hijazy from the Planning and Drug Information Department of the General Administration of Pharmacy in the MoH for her contribution in collecting the data for this study. Furthermore, we are grateful to Mr. Struan Robertson and Ms. Karin Guth for their help in editing this paper.

Funding: None.

Competing interests: None declared.

\section{References}

1. WHO policy perspectives on medicines: promoting rational use of medicines: core components. Geneva: World Health Organization; 2002 (http://apps.who.int/medicinedocs/ pdf/h3011e/h3011e.pdf, accessed 15 March 2017).

2. Hogerzeil HV. Promoting rational prescribing: an international perspective. Br J Clin Pharmacol. 1995 Jan;39(1):1-6. PMID:7756093

3. Trostle J. Inappropriate distribution of medicines by professionals in developing countries. Soc Sci Med. 1996 Apr;42(8):1117-20. PMID:8737428

4. Palestinian Ministry of Health. Palestinian national drug policy. Gaza: Ministry of Health; 1996.

5. Palestinian Ministry of Health. Palestinian essential drug list. Gaza: Ministry of Health; 2007.

6. Report of the WHO Expert Committee on National Drug Policies. Geneva, 19-23 June 1995. Contribution to updating the WHO guidelines for developing national drug policies. Geneva: World Health Organization; 1995 (http://apps.who.int/ medicinedocs/documents/s16221e/s16221e.pdf, accessed 15 March 2017).

7. Abu Mahadi A. Strategic plan for health sectors in Gaza Strip. Technical paper for Pharmacy sector. Gaza: Ministry of Health; 2013.

8. Annual report of the General Administration of Pharmacy for 2014. Gaza: Palestinian Ministry of Health. General Administration of Pharmacy; 2015.

9. Palestinian Health Information Center. Annual report of pharmacy in the Gaza Strip (2014). Gaza: Ministry of Health; 2015.

10. How to investigate drug use in health facilities: selected drug use indicators. Geneva, World Health Organization; 1993 (http://apps.who.int/medicinedocs/pdf/s2289e/s2289e. pdf, accessed 15 March 2017).

11. Shaughnessy AF, Nickel RO. Prescription-writing patterns and errors in a family medicine residency program. J Fam Pract. 1989 Sep;29(3):290-5. PMID:2769194

12. Howell RR, Jones KW. Prescription writing errors and markers: the value of knowing the diagnosis. Fam Med. 1993 Feb;25(2):104-6. PMID:8458537
13. Al Khaja KAJ, Al-Ansari TM, Sequeira RP. An evaluation of prescribing errors in primary care in Bahrain. Int $\mathrm{J}$ Clin Pharmacol Ther. 2005 Jun;43(6):294-301. PMID:15968886

14. Irshaid YM, Al Homrany M, Hamdi AA, Adjepon-Yamorah KK, Mahfouz AA. Compliance with good practice in prescription writing at outpatient clinics in Saudi Arabia. East. Mediterr. Health J. 2005 Sep-Nov;11(5-6): 922-8. PMID:16761662

15. Isah AO, Ross-Degnan D, Quick J, Laing R, Mabadeje AFB. The development of standard values for the WHO drug use prescribing indicators. World Health Organization. Essential Medicines and Policy Department. International Conference on Improving Use of Medicines (http://archives.who.int/ icium/icium1997/posters/1a2_txt.html, accessed 15 March 2017).

16. Bannenberg WJ, Forshaw CJ, Fresle D, Salami AO, Wahab HA. Evaluation of the Nile Province Essential Drugs Project: mission report by a WHO team, Sudan, 27 April-12 May, 1991. Geneva: World Health Organization; 1991 (http://apps.who.int/iris/ bitstream/10665/63301/1/WHO_DAP_91.10.pdf, accessed 15 March 2017).

17. Hogerzeil HV, Bimo, Ross-Degnan D, Laing RO, Ofori-Adjei $\mathrm{D}$, Santoso B et al. Field tests for rational drug use in twelve developing countries. Lancet. 1993 Dec 4;342(8884):1408-10. PMID:7901689

18. Mahfouz AA, Shehata AI, Mandil AM, Al-Erian RA, Al-Khuzayem AA, Kisha A. Prescribing patterns at primary health care level in the Asir region, Saudi Arabia: an epidemiologic study. Pharmacoepidemiol Drug Saf. 1997 May;6(3):197-201. PMID:15073788

19. Hamadeh GN, Dickerson LM, Saab BR, Major SC. Common prescriptions in ambulatory care in Lebanon. Ann Pharmacother. 2001 May;35(5):636-40. PMID:11346071

20. Otoom S, Batieha A, Hadidi H, Hasan M, Al-Saudi K. Evaluation of drug use in Jordan using $\mathrm{WHO}$ prescribing indicators. East. Mediterr. Health J. 2002 Jul-Sep; 8(4-5): 537-42. PMID:15603035

21. Otoom S, Culligan K, Al-Assoomi B, Al-Ansari T. Analysis of drug prescriptions in primary health care centres in Bahrain. East Mediterr Health J. 2010 May;16(5):511-5. PMID:20799550 
22. Mallet HP, Njikam A, Scouflaire SM. Evaluation of prescription practices and of the rational use of medicines in Niger. Cahiers Sante. 2001 Jul-Sep;11(3):185-94 (in French). PMID:11641083

23. Guyon AB, Barman A, Ahmed JU, Ahmed AU, Alam MS. A baseline survey on use of drugs at the primary health care leve in Bangladesh. Bull World Health Organ. 1994;72(2):265-71. PMID:8205647

24. MeyerTA. Improving the quality of the order-writing process of inpatient orders and outpatient prescriptions. Am J Health Syst Pharm. 2000 Dec 15;57 Suppl 4:S18-20. PMID:11148940

25. Bhartiy SS, Shinde M, Nandeshwar S, Tiwari SC. Pattern of prescribing practices in the Madhya Pradesh, India. Kathmandu Univ Med J. (2008 Jan-Mar;6(1):55-9. PMID:18604116

26. Palestinian Ministry of Health. Health insurance report. Gaza: Ministry of Health; 2010.
27. Rupp MT, Schondelmeyer SW, Wilson GT, Krause JE. Documenting prescription errors and pharmacist interventions in community pharmacy practice. Am Pharm. 1988 Sep;NS28(9):30-7. PMID:3177209

28. Claesson CB, Burman K, Nilsson LG, Vinge E. Prescription errors detected by Swedish pharmacies. Int J Pharm Pract. 1995 Jul;3(3):151-6.

29. Ferner RE, Aronson JK. Errors in prescribing, preparing, and giving medicines: definition, classification, and prevention. In: Aronson JK, editor. Side effects of drugs. Annual 22. Amsterdam: Elsevier; 1999:xxiii-xxxvi.

30. Al Khaja KA, Sequeira RP, Al-Ansari TM, Damanhori AH. Prescription writing skills of residents in a family practice residency programme in Bahrain Postgrad Med. J. 2008 Apr;84(990):198-204. PMID:18424577 